\title{
Juan María Wenceslao Sánchez de la Barquera Morales, primer narrador romántico
}

\author{
Alfredo Pavón \\ Universidad Veracruzana \\ pavron@yahoo.com.mx
}

\begin{abstract}
Resumen: La revisión exhaustiva del Diario de México, primer periódico del siglo xix en México, lleva a afirmar que fue el queretano Juan María Wenceslao Sánchez de la Barquera Morales el introductor, en el ámbito narrativo, del Romanticismo en dicho país. "Anécdota moral", primer relato atento a la estética romántica, publicado entre el 6 y el 7 de enero de 1806, contiene ya los motivos, temas y personajes más socorridos del movimiento, que reaparecerán en el segundo relato, "Anécdota curiosa", que vio la luz entre el 30 y el 31 de diciembre de 1806. El diseńo de ambos le gana a Sánchez de la Barquera Morales el honor de ser el primer narrador romántico mexicano.
\end{abstract}

Palabras Clave: cuento mexicano decimonónico; cuento romántico mexicano del siglo XIX; primer narrador romántico mexicano; narrativa breve romántica mexicana; Juan María Wenceslao Sánchez de la Barquera Morales.

Aвstract: The thorough revision of Diario de México, the first $19^{\text {th }}$ century newspaper in Mexico, allows the assertion that it was de Queretaro native, Juan María Wenceslao Sánchez de la Barquera Morales, who introduced romanticism in México, in the narrative field. "Anécdota moral", the first short story that took care of the romantic aesthetic was published either january 6 or 7 of 1806 , it already contained the motives, themes and most sought out characters of the movement, that will, once again appear in the short story, "Anécdota curiosa", published between december 30 and 31 of 1806 . The design of both texts, wins Sánchez de la Barquera Morales, the honor of being the first mexican romantic narrator.

KeYwORDS: Nineteenth century mexican short story; $19^{\text {th }}$ century romantic mexican short story; First mexican romantic narrator; Romantic mexican short narrative; Juan María Wenceslao Sánchez de la Barquera Morales.

FECHA DE RECEPCIÓN: 18 de septiembre de 2015

FECHA DE ACEPTACIÓN: 22 de enero de 2016

$\mathrm{C}_{\text {precisión. Para algunos, llega con José Joaquín Fernández de Lizar- }}^{1 \text { ingreso del Romanticismo a México no se ha determinado con }}$ 
di (Carballo: 50-51), Ignacio Rodríguez Galván y Fernando Calderón (Read: 49; Leal: 38; Miranda: 25; Tola, t. I: xxxv-xxxvi; Mata: 40); para otros, con José María Heredia (González 1955) y Florencio Galli (Pavón: 180-181). La lectura del Diario de México, sin embargo, arroja un dato incontrastable: el verdadero introductor de dicha estética fue Juan María Wenceslao Sánchez de la Barquera Morales (Querétaro, 22 de abril de 1779-Ciudad de México, 25 de febrero de 1840), autor, previamente, en el campo narrativo, de "El cordero y el perro", ${ }^{1}$ una fábula de escasos méritos artísticos, donde, haciendo primar lo referencial cotidiano por encima de lo estético, defiende a los editores del Diario de México de los ataques de varios detractores. Así lo testa "Anécdota moral", ${ }^{2}$ el primer relato romántico mexicano, publicado el 6 y 7 de enero de 1806.

Antecedido por "El soñador", anónimo, ${ }^{3}$ "Sobre el matrimonio y aprecio que merecen los campesinos por sus virtudes" $\mathrm{y}$ "Costumbres",,

${ }^{1}$ Juan María Wenceslao Sánchez de la Barquera Morales, "El cordero y el perro", en Diario de México (México, 18 de diciembre de 1805), t. I, núm. 79, p. 346. Firma J. w. B., iniciales que corresponden a Juan María Wenceslao Sánchez de la Barquera Morales (Manrique de Lara: 32 y 105; Ruiz Castañeda 2000: 416 y 756-757).

2 Juan María Wenceslao Sánchez de la Barquera Morales, "Anécdota moral”, en Diario de México (México, 6 de enero de 1806), t. II, núm. 98, p. 24. Firma s. c. "Sigue la anécdota moral”, en Diario de México (México, 7 de enero de 1806), t. II, núm. 99, pp. 26-28. Firma J. M. w. BarueQ, que corresponde a Juan María Wenceslao Sánchez de la Barquera Morales (Manrique de Lara: 15, 32 y 104-105; Ruiz Castańeda 2000: 102 y 756-757).

${ }^{3}$ Anónimo, "El soñador", en Diario de México (México, 20 de octubre de 1805), t. I, núm. 20, p. 79. Firma s. c. "Sigue el soñador”, en Diario de México (México, 21 de octubre de 1805), t. I, núm. 21, pp. 81-84. Firma s. c. Las iniciales s. c. fueron usadas, en el Diario de México, cuando menos por cuatro escritores. En ocasiones, por la firma final de un texto publicado en varias entregas se puede determinar la autoría de aquél; no es el caso de "El sońador" y "Sigue el sońador", por lo que se debe optar por considerarlo anónimo.

${ }^{4}$ Carlos María de Bustamante, "Sobre el matrimonio y aprecio que merecen los campesinos por sus virtudes”, en Diario de México (México, 21 de diciembre de 1805), t. I, núm. 82, pp. 356-358. Firma s. c. "Sigue el Melancólico", en Diario de México (México, 22 de diciembre de 1805), t. I, núm. 83, pp. 359-362. Firma s. c. "Concluye el melancólico”, en Diario de México (México, 23 de diciembre de 1805), t. I, núm. 84, pp. 363-365. Firma El Melancólico, que corresponde a Carlos María de Bustamante (Manrique de Lara: 41 y 68; Ruiz Castañeda 2000: 134-136 y 509).

${ }^{5}$ Carlos María de Bustamante, "Costumbres", en Diario de México (México, 2 de enero de 1806), t. II, núm. 94, pp. 6-8. Firma Una del bello sexo. Para determinar la 
ambos de Carlos María de Bustamante, donde lo romántico ya insinuaba su impronta, "Anécdota moral" —armado aún con algunos de los códigos estéticos puestos en boga por el costumbrismo moralista y el neoclasicismo, a saber, el preámbulo y la despedida del autor implícito, enmarcando la historia, continuamente contrapunteada por la postura moral de aquél-, acudía a los caracteres más notorios de dicho movimiento. A éste pertenecen la imagen de los padres comprensivos y amorosos y la de los avaros e inflexibles; el diseño del alma negra del texto, la primera de las brevedades decimonónicas mexicanas, y el del amigo fiel y sensible, testigo de las tribulaciones y sino fatídico de una joven pareja de enamorados, sino entrevisto, como será usual en el posterior Romanticismo mexicano, cuando, durante la partida de Atanasio hacia la Nueva España, se dijo a sí mismo: "Partió por fin, ¡quién sabe si para no volver a verle!" (Sánchez de la Barquera, "Anécdota moral": 24); la presencia de la joven "bella" y "virtuosa" ("Sigue la anécdota moral": 26) y la del muchacho de altos "dones naturales" ("Anécdota...": 24) — grupo de personajes sumamente interesante pues al par de los padres de los jóvenes enamorados y al del malvado traidor y el fiel amigo se les construye bajo la marca del contraste, mientras al de los amorosos, bajo el de la unidad, con lo cual se funda un motivo caro a los posteriores románticos mexicanos: la dualidad bueno/malo_-; y la historia de amor desgraciado y fatal. Serán éstos algunos de los ingredientes más usuales del primer Romanticismo, si bien el segundo no los desdeñaría del todo.

En el preámbulo, Sánchez de la Barquera Morales expone el combate entre la razón y las pasiones, éstas especialmente dañinas cuando, ya triunfantes sobre su oponente, llevan al irrenunciable amor loco, que es ilógico, amoral, espontáneo, intenso, contradictorio. También alerta contra "las almas viles" ("Anécdota...": 24), sobre todo si se enmascaran con los tintes de la amistad. La base de estas posturas morales está en la consideración del amor y la amistad como cualidades capaces de transformarse en defectos, es decir, en locura y malévolo interés, respectivamente. En esta perspectiva, son enemigos de hombres y muje-

autoría de Bustamante, se comparó "Diálogo entre la Coquetilla y su doncella", donde aparece Leonor, una escritora inteligente, sensible, prudente, y "Costumbres", donde aparece otra escritora con idénticas características. El "Diálogo entre la Coquetilla y su doncella" está firmado por La Coquetilla, seudónimo que usó Bustamante, como también lo hiciese con el de Leonor (Ruiz Castañeda 1994: 81; Ortiz: 79-96). 
res, unos enemigos soterrados, que "van siempre con nosotros mismos" (24), empleando diversas argucias "para engañarnos a nosotros mismos y sofocar los remordimientos" (24). El preámbulo, pues, explicita los contenidos centrales de "Anécdota moral", cuya historia, entonces, sería sólo una ejemplificación narrativa de los conceptos previamente vertidos. Es una debilidad textual, impuesta por la estética en boga, que, por fortuna, no afecta seriamente la historia romántica.

En dicha historia se marca el juego de contrastes usual en los románticos mexicanos posteriores. Y así, por un lado, se hallan los amorosos padres de Atanasio, preocupados por brindarle una educación perfecta "en aquellas ciencias que ilustran y perfeccionan a un caballerito de sus circunstancias" (24), dejándole en libertad para elegir cuáles de aquéllas le son más atractivas, es decir, son los padres ideales, encargados del "cuidado y educación de los hijos, desde proveer la alimentación y el vestido, hasta inculcar los más profundos valores morales y religiosos, pasando por las costumbres, tradiciones y otros elementos culturales" (Villafuerte: 31); por otro, están los padres de Clarita, ambiciosos e inflexibles, negándose al noviazgo y enlace de la joven pareja. Otro par contrapuesto es el de Gavino, hipócrita, vicioso, pérfido, intrigante, inicuo, vividor, y B., el narrador de "Anécdota moral", "dulce amigo" ("Sigue la anécdota...": 27), sensible, solidario, prudente, maduro. Uno más, pero esta vez marcado por la unidad, es el de la pareja amorosa: Atanasio y Clara. Ésta, desde la perspectiva del amado, expuesta en una carta enviada a B., es bella y virtuosa, propietaria de unos ojos expresivos, "que no quiero contemplar" pues "hacen correr por mis venas un fuego tan activo que mi pecho, cual un Edna, se difunde en gemidos inflamados" (26-27); aquél, ahora según el dulce amigo, es agradable, sensible, modesto, talentoso, aplicado, prudente, inexperto, afectuoso, educado, respetuoso, propietario, en simetría con Clarita, de "unos ojos afables y llenos de fuego atractivo" ("Anécdota...": 24). Los personajes de esta historia de amor imposible y fatal son, pues, típicos de la estética romántica, como lo es también el binomio bueno/malo, marco de las conductas y acciones de aquéllos.

El desarrollo de la diégesis pone en juego el motivo, muy romántico, del viaje, símbolo de cómo un joven feliz, hijo de "unos padres que se miraban en él como en la prenda más preciosa de su cariño" (24), termina convirtiéndose en alma desgraciada, gracias a sus yerros y a la malévola intervención del pérfido Gavino, falso amigo y "libertino descarado" 
(“Sigue la anécdota...": 27). Ese motivo era necesario para concretar, primero, al varón de templanzas lleno, triunfante ante el acoso "de la perversidad de algunos díscolos", y, después, al inexperto muchacho esclavizado por el "cruel amor" (26). En efecto, a su arribo a la capital de la Nueva Espańa, procedente de "una de las hermosas ciudades de nuestra América" ("Anécdota...": 24), "frecuentó las aulas de uno de sus más ilustres colegios, dando las pruebas más excelentes de su virtud, de su talento y de su aplicación", y venció, con su "inocencia", "la perversidad de algunos díscolos, cuyo descaro puso a prueba su virtud”, alejándose de "los ataques lisonjeros del vicio" ("Sigue la anécdota...": 26). Mas después de tales victorias, caerá en "aquella fantasía que los impulsos del corazón habían enajenado" (27), esto es, en el amor, alimentado por la expresividad de unos ojos tan bellos como enloquecedores. El proceso de enamoramiento es típico del Romanticismo: primero, el encuentro de la pareja; después, el nacimiento del amor, abonado por el continuo trato; más tarde, la crisis interior del varón al descubrirse esclavo de las pasiones, compañera de dolidas reflexiones sobre el destino de los hombres sujetos a éstas; posteriormente, las mutuas declaraciones de amor, por desgracia realizadas a espaldas de los padres de Clara, motivo de la culpabilidad moral de Atanasio, cuyas "lágrimas, que mil veces he derramado a los pies de los altares", apenas le "comunican alguna tranquilidad" (27). La culpabilidad no sólo se desprende de la transgresión a dos de las reglas del noviazgo, la anuencia de los padres y la socialización del amor de la pareja, sino también de los insinuados tintes erótico-sexuales que hay entre ella y él. Son estos ingredientes prohibidos, propios de la carne perversa, los augures de la caída moral, "las imágenes funestas de mi destrucción" (27), combatidos magramente con las visitas a los altares religiosos y con la solicitud de ayuda al amigo lejano, buscando recuperar la fortaleza y conservar la virtud.

Mientras se concreta el arribo del amigo, Atanasio se ve obligado, no sin reticencias, a apoyarse en Gavino, el genio del mal: "¿Quién sabe si este joven recién llegado podrá hacer conmigo tus oficios?” (27). Para entonces, el amor correspondido es una realidad, aunque se evite todo contacto físico, como lo es también la férrea oposición familiar: "Las circunstancias no permitían un enlace; los padres de Clarita tenían otras miras: eran ambiciosos" (27). De estos detalles habrá de enterarse Gavino, gracias a las abrumadas confesiones del héroe. Intrigante y guiado por mezquinos intereses, derrumba totalmente las bases morales 
de aquél, impulsa el contacto directo entre los enamorados y apoya la desobediencia a los padres de la joven, cuyo término es la fuga con el amado:

hace que Atanasio se olvide aquellos auxilios que tenía, superiores a toda pasión; y como un abismo conduce a otro abismo, franquea éste a su libertad las fuertes cerraduras del pundonor, mira entre cautelas a Clarita, descubre en un momento todo el fuego que ocultaba y se juntan dos incendios, cuya voracidad consume a dos inocentes, víctimas de un solo instante. Atanasio y Clara: ¡qué horror! Aquél abandona el tesoro de su virtud y ésta huye de sus padres, inconsiderablemente (27).

La caída moral de la pareja se ha cumplido, trayendo el deshonor a los padres: a los de Atanasio, por el fracaso del hijo en cuanto a los proyectos educativos y por la traición a las virtudes transmitidas; a los de Clarita, por los amores clandestinos y la fuga con el amante. De todo esto es culpable, en gran medida, el alma negra de "Anécdota moral", cuyo papel maléfico aún no concluye. Anticipándose a la huida, secuestra a la dama y la viola:

El malvado amigo, que había tramado este lance con las miras más inicuas, se anticipa a la fuga, con la presa y el tesoro que se había reservado en aquel fatal momento, y se abandona a las mayores infamias que podían esperarse de un libertino descarado. Gime inútilmente la desgraciada Clarita en manos de la violencia más inicua; y cuando llega Atanasio, es sólo para mirar su deshonra (27-28).

Ingresó, así, a la narrativa mexicana decimonónica un motivo prohibido, el del estupro, que, más tarde, aparecerá esporádicamente y de modo velado, por ejemplo, en "Historia de un salteador italiano", de José María Heredia (9-18). Era un motivo necesario para darle cima a la perfidia de Gavino y para amonestar textualmente a los amantes transgresores — propósito ideológico de Sánchez de la Barquera Morales y de sus continuadores dentro del Romanticismo: el mal siempre se castiga-, a quienes hicieron posible la caída en lo prohibido y a quienes, aunque deseándolo, no pudieron impedirlo. Así, Clarita pierde al amado, es violada y queda en la soledad absoluta, convirtiéndose en aquella que no está limpia de pecado; Atanasio, el inmortal, al ver mancillada a su amada entra en shock emocional y muere: "Quiere embestir contra el pérfido, pero sus ojos se cubren de unas sombras mortales. Sus miem- 
bros temblorosos, cubiertos de un sudor frío, no hallan dónde apoyarse. Aquel fuego, que consume sus entrañas, le impide la respiración y le sofoca. Precipitadamente, cae junto a su amable Clarita, a quien un desmayo tenía sin sentido, y allí exhala el último aliento" "Sigue la anécdota...": 28); los padres de Atanasio caen en el deshonor y el sufrimiento, culpables, si culpables son, de no actuar a tiempo a fin de alejar a Atanasio "de peligro tan inminente" (27), como también ocurre al amigo de la juventud, B., por las mismas causas; el gavillero Gavino, aunque no lo explicita el texto, vivirá, a partir del estupro cometido, o en la cárcel o en la fuga continua. Es una escena final desolada, propia de los románticos mexicanos, para quienes nadie se salva cuando el orden social y familiar ha sido maculado; una clausura diegética donde el diálogo entre lo estético y lo ideológico es perfecto, convirtiendo a "Anécdota moral" en un relato romántico maduro y propositivo, sorprendente si se asume que fue el primero de esta estirpe.

Ahora bien, si la historia de "Anécdota moral" es buena en su armado, el texto en conjunto no. El preámbulo peca de explicativo o, si se quiere, tiene su base en las palabras de más que todo narrador debe evitar; las reflexiones morales sobre la destructividad del amor loco, a cargo del autor implícito, incrustadas entre el informe de los antecedentes familiares y vivenciales de Atanasio y la carta de éste solicitando ayuda espiritual a B., detienen el fluir de lo contado y adensan la lectura; el final desplaza la historia de amor imposible y fatal para darle protagonismo al lacrimoso narrador, B., y para dar pie al moralismo romántico y a uno de sus caracteres más socorridos: la exacerbada sensibilidad: "Lágrimas: vosotras sois el único tributo que ha quedado a la amistad, y que usted sabrá apreciar, señor editor, si es tan sensible como su afectísimo servidor" (28). Estos excesos no invalidan la historia romántica, pero sí la acompañan mal. Son el tributo pagado por Sánchez de la Barquera Morales a las modas literarias de su tiempo, desdeñable si se remite a lo estrictamente narrativo; apreciable si se aspira a comprender el orden social, cultural y moral de los inicios del siglo xIx.

Antes de arribar a su segundo relato romántico, Sánchez de la Barquera Morales publicó "La amistad. Rasgo moral" — — donde el problema

${ }^{6}$ Juan María Wenceslao Sánchez de la Barquera, "La amistad. Rasgo moral”, en Diario de México (México, 17 de julio de 1806), t. III, núm. 290, pp. 317-320. Firma Juan María Wenceslao Sánchez de la Barquera. 
central es la idea de la amistad como único refugio contra los sinsabores de la vida—, "Integridad heroica de Licurgo. Anécdota moral" — un texto híbrido, mitad ensayístico, mitad narrativo, en el cual, amén de tocar un tema escabroso para la época: el aborto, alabó virtudes como la fidelidad e integridad-y "Ejemplo heroico de amistad" 8 —un relato, por su temática y técnica, en franca secuencia" con "La amistad. Rasgo moral" e "Integridad heroica de Licurgo. Anécdota moral", donde retomó la temática de la amistad, ya falsa, ya verdadera. En ellos, fue afinando habilidades narrativas y preferencias estéticas, entre ellas, si temporalmente, la romántica. De la mano de ésta, escribirá "Anécdota curiosa", ${ }^{10}$ en el cual reitera la fórmula creativa empleada en los ante-

${ }^{7}$ Juan María Wenceslao Sánchez de la Barquera Morales, "Integridad heroica de Licurgo. Anécdota moral", en Diario de México (México, 1 de diciembre de 1806), t. IV, núm. 427, pp. 377-378. Firma Barquera, apellido que corresponde a Juan María Wenceslao Sánchez de la Barquera Morales (Ruiz Castañeda 2000: 756-757).

${ }^{8}$ Juan María Wenceslao Sánchez de la Barquera Morales, "Ejemplo heroico de amistad”, en Diario de México (México, 5 de diciembre de 1806), t. Iv, núm. 431, pp. 392-394. Firma Barquera.

${ }^{9}$ El fenómeno de las secuencias cuentísticas ha sido seriamente estudiado por Russell M. Cluff, quien, basándose en las reflexiones de Robert M. Luscher, propone para el estudio de este fenómeno literario las siguientes bases:

La secuencia de cuentos consta de un conjunto de cuentos y no capítulos — que 1) refuerzan entre sí los mismos contextos, personajes, símbolos o temas. Y esto se realiza sin que los cuentos individuales pierdan su autonomía. 2) La secuencia depende de una variedad de estrategias textuales para proveer unidad y coherencia. Para lograr esto se suelen usar técnicas tales como un título unificador, un prefacio, un epígrafe o cuentos enmarcadores. Además, las distintas obras pueden tener en común elementos más orgánicos, como los siguientes: narradores, personajes, imágenes, ambientes o temas. 3) Los cuentos pueden adquirir mayor coherencia entre sí mediante ciertos patrones estructurales relacionados con el contrapunto, la yuxtaposición o una secuencia temporal no muy apretada. 4) El conjunto también debe haber sido armado por el mismo autor y no por algún antologador que, lógicamente, no podría descifrar las intenciones de ese autor en cuanto a la relación entre los cuentos que forman el volumen (Cluff, especialmente "Colonizadores y colonizados en Zitilchén: la secuencia cuentística de Lara Zavala” [259-284] y "Doce peregrinajes maravillosos" [337-355]; Luscher: 148-167).

${ }^{10}$ Juan María Wenceslao Sánchez de la Barquera Morales, "Anécdota curiosa", en Diario de México (México, 30 de diciembre de 1806), t. Iv, núm. 456, pp. 492-494. Sin firma. "Anécdota", en Diario de México (México, 31 de diciembre de 1806), t. IV, núm. 457, pp. 496-497. Firma Barquera. 
cesores: primero, un preámbulo ensayístico, esta vez con una escritura deudora del Barroco; después, el despliegue de lo narrativo, donde ocupan lugar dominante la historia trágica, los personajes antitéticos con destinos funestos y la presencia del secreto, cuya develación llevará al tratamiento del incesto, todos ellos ingredientes del posterior Romanticismo mexicano canónico.

En el preámbulo, Sánchez de la Barquera Morales alaba la benevolencia de Dios hacia mujeres y hombres, quienes, al optar por el libre albedrío o "libertad humana" ("Anécdota curiosa": 492), contravienen los designios divinos y ven "constantemente frustrados todos sus proyectos, sin poderlo remediar" (492). El sino fatal de aquéllos viene, pues, de su personalidad, relaciones interpersonales, pasiones, decisiones, actos y las consecuencias derivadas de éstos, un sino inevitable que ellos se construyen u obedecen, tomando, a veces, un "rumbo opuesto" al predicho por "la providencia divina" (492). El intelectual católico, como Sánchez de la Barquera Morales lo era, busca negar la responsabilidad de su Dios en el destino funesto tanto de los protagonistas de "Anécdota curiosa" como de las personas reales que les dieron origen, pues, confiesa, la historia de su relato es una "cuya verdad tengo bastantemente acreditada" (492). Y para ello, argumenta: "Así como hay ciertas desgracias entre los hombres que se contraen por el vicio o por la falta de reflexión, hay también otras inevitables, que están vinculadas al destino de ciertas personas que, aun a pesar de su inocencia y buena conducta, llevan siempre consigo el sello de la desgracia y mal suceso en todas sus acciones" (492). Concluyendo después: la caída humana no es producto "del fatalismo que sostuvo la gentilidad", sino de "las diversas combinaciones que contribuyen al buen o mal éxito que se oculta a la prudencia humana" (492). De ahí desprende: Dios es benevolente; mujeres y hombres construyen su historia, en ocasiones contraviniendo la voluntad divina; cuanto éstos hacen contribuye "sobremanera a su felicidad" (492), aun cuando sea por vía de los yerros y perjuicios, pues de todo "mal resulta el bien" (492). Así, Sánchez de la Barquera Morales respondía al posible cuestionamiento sobre la permisividad divina en un caso de incesto donde los involucrados eran inocentes, evitando, además, la condena de éstos pues habían caído en pecado nefasto por culpa de su madre, que había procreado a la desgraciada hija después de una "fragilidad en su juventud" ("Anécdota": 497), entregándola más tarde "a la casa de expósitos" (497). Como antes lo había hecho 
con el tratamiento de la violación, en "Anécdota moral", y del aborto, en "Ejemplo heroico de amistad", en "Anécdota curiosa", ahora con el tema del incesto, este intelectual católico y conservador y escritor de avanzada puso la infalibilidad divina por encima de los aciertos y yerros humanos, sin por ello dańar, al menos no del todo, las cualidades estéticas de su obra.

Ya en el campo narrativo, Sánchez de la Barquera Morales abrevará en los caracteres más socorridos del Romanticismo. Así, creará una antítesis con los padres de los protagonistas mediante la dualidad buenos/ malos. En efecto, los padres de Nicandro serán - especialmente el padre- modelo de la maternidad-paternidad decimonónica: virtuosos, salvo por el error de juventud de la madre, que se ha redimido mediante una posterior vida austera, prudente y apegada a las buenas maneras y conductas; preocupados por brindarle al vástago apoyo económico, moral, educativo y afectivo; compañeros del hijo cuando éste desea construir su universo amoroso. Por su parte, de los padres de Rufina se señala la ausencia materna —un motivo usual en los próximos románticos- y la presencia paterna, un "padre anciano, ambicioso y avaro, de aquellos que para colocar a sus hijas atienden más al interés que a la virtud de los que han de decidir su destino" ("Anécdota curiosa”: 492). Es la contracara del bueno y benévolo progenitor del protagonista masculino de "Anécdota curiosa" pues, por atender sólo los llamados del interés económico, se olvida de darles a sus dos hijas valores e ideales, tarea encomendada, por esos días, a la madre.

Otra antítesis está formada por Nicandro-Julieta y Rufina. Ésta, "que había heredado el orgullo de su padre" (493), es una joven ambiciosa, calculadora y vanidosa, capaz de aceptar "una unión más brillante, con un joven rico y distinguido, cuyos padres habían pactado con el suyo aquel enlace aun antes de conocerse los contrayentes" (493). Frente a ella, se halla Julieta, la niña expósita "que se había criado con Rufina" ("Anécdota": 496), hermosa, humilde, decente, modesta, inocente, tímida, digno par de Nicandro, a quien el narrador describe como un muchacho de "fina educación" ("Anécdota curiosa": 492), prudente, amable, amoroso, franco, sensible, bondadoso, de carácter firme. Con esta tríada, Sánchez de la Barquera Morales, de la mano de la estética romántica, completaba el cuadro de personajes para su trágica historia.

¿Cómo se armó dicha diégesis? La base narrativa es, primero, un juego de contrastes de fortuna, en el cual la tragedia de una familia tiene 
su contrapunto con el ascenso de la otra y, después, un juego de alternancias, en el cual a la consumación de la desgracia sigue, si sólo como paliativo, el reordenamiento de la existencia familiar y personal, no así el de la pareja. El primer cambio de fortuna del texto es el paso de "la opulencia" a la economía precaria, "una pequeña renta, que quedó a la madre", provocado todo por "los vicios de un dependiente de la casa" (492). Esa caída familiar, cuando Nicandro tiene sólo dieciséis años, está acompañada de la vejez del padre, "muy cansado para el trabajo", y de la inexperiencia del joven para asumir funciones paternas, como la de hacer "girar aquel corto capital", circunstancias ambas que obligan a una decisión: "cursar leyes en un colegio de los más acreditados, para así asegurar su subsistencia en un carrera decorosa" (492). Mientras los estudios se cumplen, el protagonista se enamora de Rufina, a quien, debido a la precaria economía, no confiesa su amor: "temeroso de una repulsa y acobardado con la pobreza de su suerte, no se atrevía a declarar su pasión" (493). Del enamoramiento, se desprenderá ahora la caída afectiva, con el agregado horror de implicar la pérdida de la amistad sostenida con las "dos señoritas jóvenes, que vivían al cuidado de su padre anciano", que "había comenzado a ser rico en compañía del de Nicandro" (492). Apoyado por su padre y por la falsa idea del amor correspondido, vencerá miedos y dubitaciones, planeando "un enlace ventajoso a su virtud y a su comodidad" (493), propósito fallido pues Rufina y su padre, amén del compromiso matrimonial ya pactado con otra familia, sólo aspiran a la riqueza y el lujo, que no podría brindarles quien apenas si posee medios para subsistir. Mas las desdichas aún no concluyen. Seis meses más tarde de cuando el padre de Rufina rechazó y denigró la petición matrimonial, mientras "se verifica el enlace, con universal regocijo de la familia" de aquélla, "el padre de Nicandro es arrebatado por una fiebre, sin poderlo volver los cuidados más eficaces de la medicina y las atenciones de su familia” (494). Así, el sufrimiento de unos va aparejado con la felicidad de los otros. Es entonces cuando el narrador decide invertir el proceso. Esta vez, caerá de lo más alto quien sólo parabienes tenía y ascenderá quien sólo sinsabores degustaba. En efecto, "sucede en la casa de Rufina el trastorno que era consecuente a los ambiciosos principios de su unión: su marido, joven atolondrado y vicioso, disipa su patrimonio en el seno de la disolución y arruina también gran parte de los haberes de su esposa" ("Anécdota": 496), derrumbe contrastado ahora con la estabilidad económica y afectiva de 
Nicandro - el hombre victorioso- y su madre, generada por la conclusión de los estudios de leyes de aquél. Junto con la caída de Rufina, su familia y su pareja, se produce también la de Julieta, la "joven huérfana” (496), criada con aquélla. A fin de subsistir, acude con Nicandro, quien le brinda asilo. Y no sólo eso, también encuentra ternura y amor en la madre de aquél y, más tarde, gracias al trato cotidiano, "un amor honesto y vivo" (496) en el protagonista, y, finalmente, previo acuerdo entre progenitora e hijo, el pedimento matrimonial y "la unión de aquellos corazones tiernos" (496). Con el enlace, culmina el camino hacia el regocijo. Es el momento elegido por el narrador para dar paso a la desgracia, anticipado con sutil prolepsis, una de las técnicas más usuales, junto con la de la analepsis, de los románticos del segundo tercio del siglo XIX, con la cual se solía quebrar la linealidad narrativa o principio aristotélico. Para concretar este momento, echa mano del secreto, a saber, "el funesto fruto de una fragilidad" de juventud de la madre. Y con él, develado con el recurso de la súbita enfermedad de Julieta, que se presenta "a pocos días de verificado el matrimonio, cuando la felicidad reinaba en el centro de aquella familia" y consumado ya el "trato conyugal" entre la pareja, llegan el dolor y la separación, causados por el descubrimiento del incesto: la hija de dieciocho años, la huérfana abandonada en una "casa de expósitos" (497), es hermana de Nicandro. Es la caída abismal, absoluta; es el caos impensado. Lo sigue una precaria recomposición familiar y una no menos precaria recomposición individual, alcanzada mediante ejercicios de expiación: "Julieta sana y vive en el seno de su madre, sin olvidar jamás a su amado Nicandro, pero éste acaba sus días en una religión, disfrutando la felicidad más sólida, debida a su virtud" (497). Con esta alternancia, orden-caos-orden nuevo, cierra Sánchez de la Barquera Morales una historia signada por lo fatal.

Historia, personajes y contexto social y moral de éstos fueron construidos con los caracteres del futuro Romanticismo canónico mexicano: lenguaje lacrimoso para situaciones narrativas lacrimosas; ruptura de la linealidad aristotélica mediante el recurso de las analepsis y prolepsis; continuas reflexiones morales del autor implícito sobre el material diegético; tratamiento del amor y sus derroteros y del incesto; convocatoria del secreto como detonante de la desgracia; presencia de la transgresora joven inexperta, cuyos amores prohibidos llevan a la maternidad culpable, al parto clandestino y al abandono del recién nacido, retomados, 
años más tarde, estos ingredientes, junto con los del incesto y el secreto, por José Joaquín Pesado en "El amor frustrado" (13-50); construcción antitética de personajes; contraste entre padre responsable y virtuoso y padre desobligado y ambicioso; ausencia de la madre; pacto matrimonial entre familias sin consulta de los futuros contrayentes; heroína hermosa, angelical y pura y heroína vanidosa y egoísta; héroe inmaculado, suma de todas las virtudes, pero destinado a la desgracia, y héroe imprudente y vicioso, también con sino funesto; jóvenes cuyas edades fluctúan entre los dieciséis y dieciocho ańos. Nadie, pues, puede regatear el papel de introductor del Romanticismo en México a Sánchez de la Barquera Morales, un ingreso nada tardío a este país, como bien lo prueba su "Anécdota curiosa", de 1806, donde supuestamente transformó hechos reales en universo literario.

Después de escribir "Anécdota moral" y "Anécdota curiosa", el creador queretano abjuró del Romanticismo, quizá porque fue objeto de varias recriminaciones por parte de los lectores y de sus compañeros en la Arcadia Mexicana, derivadas de su gusto por una estética marginal en ese momento, que atendía asuntos moralmente candentes y prohibidos en el México decimonónico: el estupro, el aborto y el incesto. Mas la cabra siempre tira al monte. Aunque Sánchez de la Barquera Morales tornó al costumbrismo y a los textos didácticos y morales de su etapa narrativa inicial —verbigracia, la fábula "El cordero y el perro" y los relatos "La amistad. Rasgo moral", "Integridad heroica de Licurgo. Anécdota moral" y "Ejemplo heroico de amistad" - y recaló en el neoclasicismo — con "Fuerza del amor. Idilio primero", "El niño Atay. Idilio segundo", "La prudencia. Anécdota cuarta", 11 "El novio cantor.

${ }^{11}$ El subtítulo "Anécdota cuarta" supone el antecedente de las anécdotas primera, segunda y tercera, que, firmadas por Sánchez de la Barquera Morales, no existen; sí, a cambio, se publicaron, en el Diario de México, con la firma de Juan María Lacunza. Se trata, sin duda, de un juego acordado entre ambos creadores: escribir una serie de anécdotas para el Diario de México, correspondiendo las tres primeras a Lacunza y las siguientes — cuarta, quinta, sexta, séptima y octava — a Sánchez de la Barquera Morales. Véase Juan María Lacunza, “Anécdota”, en Diario de México (México, 13 de octubre de 1807), t. viI, núm. 744, p. 201. Firma Can-Azul. Juan María Lacunza, "Anécdota segunda", en Diario de México (México, 3 de noviembre de 1807), t. viI, núm. 765, pp. 284-285. Firma Can-Azul. "Anécdota”, en Diario de México (México, 23 de marzo de 1808), t. viII, núm. 906, pp. 231-232. Sin firma. Para determinar al autor de esta "Anécdota" sin firma fue necesario retomar los títulos originales de los tres textos de Lacunza: "Anécdota”, “Anécdota segunda. Núm. 744” y "Anécdota. Núm. 765”. La 
Idilio tercero", "La sinceridad. Anécdota quinta", "La fortaleza. Anécdota sexta" "La romería del Tepeyac. Idilio cuarto", "La vana confianza. Anécdota séptima", "La gratitud desgraciada. Anécdota octava", "El madrugador. Idilio quinto", "Idilio", "Jacinto y Mirtilo. Idilio sexto" y "La voz de la razón. Idilio séptimo. Micon y Lidas"—, ${ }^{12}$ no calló del todo su afición por lo novedoso y moderno del Romanticismo, aunque éste fuese ya tangencial por relación a lo costumbrista y a lo neoclásico. Así lo testan "Fuerza del amor. Idilio primero" — con la temática del amor imposible y las imposiciones de los padres a los hijos en el momento de la elección de la pareja-y "La gratitud desgraciada. Anécdota oc-

indicación "Núm. 744" corresponde a la primera "Anécdota", publicada el 13 de octubre de 1807; la "Núm. 765", a la "Anécdota segunda", publicada el 3 de noviembre de 1807, ambas firmadas por Can-Azul. La tercera "Anécdota", sin firma, siguiendo la numeración arriba indicada, corresponde, pues, a Lacunza, quien se preocupó, así, por remitir a sus obras anteriores, marcando con ello las tres anécdotas que aportó a la serie de siete que acordó publicar con Sánchez de la Barquera Morales. Una última aclaración conviene traer a escena: el seudónimo Can-Azul corresponde a Juan María Lacunza (Ruiz Castañeda 2000: 154 y 432-433).

${ }^{12}$ Juan María Wenceslao Sánchez de la Barquera Morales, "Fuerza del amor. Idilio primero", en Diario de México (México, 12 de agosto de 1807), t. vi, núm. 682, pp. 414-416. Firma El Zagal Quebrara. "El niño Atay. Idilio segundo", en Diario de México (México, 27 de agosto de 1807), t. vi, núm. 697, pp. 473-475. Firma El Zagal Quebrara. "La prudencia. Anécdota cuarta", en Diario de México (México, 20 de septiembre de 1807), t. viI, núm. 720, pp. 78-80. Firma J. M. W. Barquera. "El novio cantor. Idilio tercero”, en Diario de México (México, 23 de octubre de 1807), t. viI, núm. 754, pp. 239-241. Firma El Zagal Quebrara. "La sinceridad. Anécdota quinta”, en Diario de México (México, 9 de noviembre de 1807), t. viI, núm. 771, pp. 308-310. Firma J. M. W. Barquera. "La fortaleza. Anécdota sexta", en Diario de México (México, 16 de noviembre de 1807), t. viI, núm. 778, pp. 335-338. Firma J. M. W. Barquera. "La romería del Tepeyac. Idilio cuarto”, en Diario de México (México, 14 de diciembre de 1807), t. viI, núm. 806, pp. 447-449. Firmado por El Zagal Quebrara. "La vana confianza. Anécdota séptima”, en Diario de México (México, 29 de diciembre de 1807), t. VII, núm. 821, pp. 307-310. Firma J. W. Barquera. "La gratitud desgraciada. Anécdota octava”, en Diario de México (México, 25 de febrero de 1808), t. viII, núm. 879, pp. 122124. "Concluye la anécdota", en Diario de México (México, 26 de febrero de 1808), t. viII, núm. 880, pp. 126-128. Firma J. W. B. "El madrugador. Idilio quinto”, en Diario de México (México, 29 de abril de 1808), t. viII, núm. 943, pp. 376-377. Sin firma. "Idilio", en Diario de México (México, 30 de abril de 1808), t. viII, núm. 944, pp. 382384. Firma El Zagal Quebrara. "Jacinto y Mirtilo. Idilio sexto", en Diario de México (México, 6 de mayo de 1808), t. viII, núm. 950, pp. 405-407. Firma El Zagal Quebrara. "La voz de la razón. Idilio séptimo. Micon y Lidas", en Diario de México (México, 19 de junio de 1808), t. viII, núm. 994, pp. 584-586. Firma El Zagal Quebrara. 
tava" - con motivos como la violencia, el suicidio y el presentimiento de futuras desgracias, desprendimientos de los relatos fundacionales del Romanticismo mexicano: "Anécdota moral" y "Anécdota curiosa".

Juan María Wenceslao Sánchez de la Barquera Morales, pues, fue uno de los fundadores de la narrativa breve mexicana decimonónica; el osado introductor del Romanticismo en México, aunque, después, lo abandonara; uno de los pioneros en el uso de recursos innovadores para su época: la secuencialidad, la intratextualidad y el hibridismo; un narrador rebelde, irregular, contradictorio, atrevido, conservador, vanguardista y propositivo — nada mal para un periodo en que la narrativa mexicana era, en apariencia, poco original, dubitante, superficial y malograda. Sea este escrito el primero de muchos homenajes que se le deben a Sánchez de la Barquera Morales, como también lo merecen otros que, en esos años difíciles del parto de una nación, fueron suma de inteligencia y fantasía: José Antonio Reyes, Mariano Barazábal, Francisco Manuel Sánchez de Tagle Varela, Payno de Bustamante, Luis de Mendizábal, Francisco Palacios, Vicente Herrera, Manuel de la Torre Lloreda Palacio, Joaquín Conde, José Mariano Rodríguez del Castillo, Ramón Quintana del Azebo, Jacobo de Villaurrutia, José Manuel Martínez de Navarrete, Juan María Lacunza y Josef Manuel de Dávila, además de los varios creadores anónimos.

\section{BibLIOHEMEROGRAFÍA}

Anónimo. "El soñador", en Diario de México. México, 20 de octubre de 1805. T. I, núm. 20. "Sigue el soñador", en Diario de México. México, 21 de octubre de 1805. T. I, núm. 21.

Bustamante, Carlos María de. "Costumbres", en Diario de México. México, 2 de enero de 1806. T. II, núm. 94.

Bustamante, Carlos María de. "Sobre el matrimonio y aprecio que merecen los campesinos por sus virtudes", en Diario de México. México, 21 de diciembre de 1805. T. I, núm. 82. "Sigue el Melancólico", en Diario de México. México, 22 de diciembre de 1805. T. I, núm. 83. "Concluye el melancólico”, en Diario de México. México, 23 de diciembre de 1805. T. I, núm. 84.

Carballo, Emmanuel. Historia de las letras mexicanas en el siglo XIX. Guadalajara: Universidad de Guadalajara / Xalli, 1991. 
Cluff, Russell M. Los resortes de la sorpresa (Ensayos sobre el cuento mexicano del siglo XX). Tlaxcala: Universidad Autónoma de Tlaxcala / Brigham Young University, 2003.

González, Manuel Pedro. José Maria Heredia, primogénito del Romanticismo hispano. Ensayo de rectificación histórica. México: El Colegio de México, 1955.

Heredia, José María. "Historia de un salteador italiano", en Miscelánea. Periódico crítico y literario. Toluca, junio de 1831. Segunda época. T. I, núm. 1.

Lacunza, Juan María. "Anécdota”, en Diario de México. México, 13 de octubre de 1807. T. VII, núm. 744.

Lacunza, Juan María. "Anécdota", en Diario de México. México, 23 de marzo de 1808. T. VIII, núm. 906.

Lacunza, Juan María. “Anécdota segunda”, en Diario de México. México, 3 de noviembre de 1807 . T. VII, núm. 765.

Lara, Juana Manrique de y Guadalupe Monroy Baigen. Seudónimos, anagramas e iniciales de escritores mexicanos antiguos y modernos. México: 1954.

Leal, Luis. Breve historia del cuento mexicano. México: Eds. de Andrea, 1956.

Luscher, Robert M. “The Short Story Sequence: An Open Book”, en Norman Friedman y otros. Short Story Theory at a Crossroads. Ed. de Susan Lohafer y Jo Ellyn Clarey. Baton Rouge y Londres: Louisiana State Univesity Press, 1989.

Mata, Óscar. La novela corta mexicana en el siglo XIX. México: Universidad Nacional Autónoma de México, 1999.

Miranda CÁrabes, Celia. "Estudio preliminar" a La novela corta en el primer Romanticismo mexicano. Est. prel. de Celia Miranda Cárabes. "La novela corta de la Academia de Letrán” de Jorge Ruedas de la Serna. México: Universidad Nacional Autónoma de México, 1985.

Ortiz Domínguez, Efrén. "Travestismo poético en el siglo XIX”, en ConNotas. Revista de crítica y teoría literarias. Hermosillo, Universidad Autónoma de Sonora, 2003. Vol. I, núm. 1.

Pavón, Alfredo. Al final. Recuento I. Orígenes del cuento mexicano: 18141837. México: Universidad Autónoma Metropolitana-Iztapalapa / Benemérita Universidad Autónoma de Puebla, 2004.

Pesado, José Joaquín. “El amor frustrado”, en El Año Nuevo de 1838. Presente Amistoso. México, Imprenta de Mariano Galván, 1838.

ReAd, J. Lloyd. The Mexican Historical Novel 1826-1910. Nueva York: Instituto de las Españas en los Estados Unidos, 1939.

Ruiz Castañeda, María del Carmen. "Mujer y literatura en la hemerografía: revistas literarias femeninas del siglo XIX", en Fuentes humanisticas. 
México: Universidad Autónoma Metropolitana - Azacapotzalco, enerojunio de 1994. Año 4, núm. 8.

Ruiz Castañeda, María del Carmen y Sergio Márquez Acevedo. Diccionario de seudónimos, anagramas, iniciales y otros alias. Usados por escritores mexicanos y extranjeros que han publicado en México. México: Universidad Nacional Autónoma de México, 2000.

Sánchez de la Barquera Morales, Juan María Wenceslao. "La amistad. Rasgo moral”, en Diario de México. México, 17 de julio de 1806. T. III, núm. 290.

Sánchez de la Barquera Morales, Juan María Wenceslao. "Anécdota curiosa”, en Diario de México. México, 30 de diciembre de 1806. T. IV, núm. 456. "Anécdota", en Diario de México. México, 31 de diciembre de 1806. T. IV, núm. 457.

Sánchez de la Barquera Morales, Juan María Wenceslao. "Anécdota moral”, en Diario de México. México, 6 de enero de 1806. T. II, núm. 98. "Sigue la anécdota moral", en Diario de México. México, 7 de enero de 1806. T. II, núm. 99.

Sánchez de la Barquera Morales, Juan María Wenceslao. "El cordero y el perro", en Diario de México. México, 18 de diciembre de 1805. T. I, núm. 79.

Sánchez de la Barquera Morales, Juan María Wenceslao. "Ejemplo heroico de amistad", en Diario de México. México, 5 de diciembre de 1806. T. IV, núm. 431.

Sánchez de la Barquera Morales, Juan María Wenceslao. "La fortaleza. Anécdota sexta”, en Diario de México. México, 16 de noviembre de 1807. T. VII, núm. 778.

Sánchez de la Barquera Morales, Juan María Wenceslao. "Fuerza del amor. Idilio primero", en Diario de México. México, 12 de agosto de 1807. T. VI, núm. 682.

Sánchez de la Barquera Morales, Juan María Wenceslao. "La gratitud desgraciada. Anécdota octava”, en Diario de México. México, 25 de febrero de 1808. T. VIII, núm. 879. "Concluye la anécdota”, en Diario de México. México, 26 de febrero de 1808. T. VIII, núm. 880.

Sánchez de la Barquera Morales, Juan María Wenceslao. "Idilio", en Diario de México. México, 30 de abril de 1808. T. VIII, núm. 944.

Sánchez de la Barquera Morales, Juan María Wenceslao. "Integridad heroica de Licurgo. Anécdota moral”, en Diario de México. México, 1 de diciembre de 1806. T. IV, núm. 427.

Sánchez de la Barquera Morales, Juan María Wenceslao. "Jacinto y Mirtilo. Idilio sexto", en Diario de México. México, 6 de mayo de 1808. T. VIII, núm. 950. 
Sánchez de la Barquera Morales, Juan María Wenceslao. "El madrugador. Idilio quinto", en Diario de México. México, 29 de abril de 1808. T. VIII, núm. 943.

Sánchez de la Barquera Morales, Juan María Wenceslao. "El nińo Atay. Idilio segundo", en Diario de México. México, 27 de agosto de 1807. T. VI, núm. 697.

Sánchez de la Barquera Morales, Juan María Wenceslao. "El novio cantor. Idilio tercero", en Diario de México. México, 23 de octubre de 1807. T. VII, núm. 754.

Sánchez de la Barquera Morales, Juan María Wenceslao. "La prudencia. Anécdota cuarta", en Diario de México. México, 20 de septiembre de 1807. T. VII, núm. 720.

Sánchez de la Barquera Morales, Juan María Wenceslao. "La romería del Tepeyac. Idilio cuarto", en Diario de México. México, 14 de diciembre de 1807. T. VII, núm. 806.

Sánchez de la Barquera Morales, Juan María Wenceslao. "La sinceridad. Anécdota quinta", en Diario de México. México, 9 de noviembre de 1807. T. VII, núm. 771.

Sánchez de la Barquera Morales, Juan María Wenceslao. "La vana confianza. Anécdota séptima”, en Diario de México. México, 29 de diciembre de 1807. T. VII, núm. 821.

Sánchez de la Barquera Morales, Juan María Wenceslao. "La voz de la razón. Idilio séptimo. Micon y Lidas”, en Diario de México. México, 19 de junio de 1808. T. VIII, núm. 994.

Tola de Habich, Fernando. "Diálogo sobre los Año Nuevo y la Academia de Letrán", en El Año Nuevo de 1837. T. I. Est. prel. de Fernando Tola de Habich. México: Universidad Nacional Autónoma de México, 1996.

Villafuerte García, Lourdes. "Entre dos amores. Problemas de novios en el siglo xvir", en Sergio Ortega Noriega y otros, Amor y desamor. Vivencias de parejas en la sociedad novohispana. México: Instituto Nacional de Antropología e Historia, 1999. 